\title{
Developing Scholarship of Teaching and Learning through a Community of Enquiry
}

\author{
Vivienne Bozalek*, Arona Dison*, Melanie Alperstein^^ and Veronica Mitchell^ \\ * University of the Western Cape, South Africa \\ $\wedge$ University of Cape Town, South Africa
}

(Received 3 March 2017; accepted 16 October 2017)

\begin{abstract}
A growing interest in the Scholarship of Teaching and Learning (SoTL) in higher education requires the seeking of opportunities for its development within and across disciplines and institutions. However, rewards for individual competitiveness in research publications, including the Scholarship of Teaching and Learning (SoTL), tend to discourage collaboration, which could be highly conducive to the development of SoTL. This paper proposes the value of working together in a collaborative community of enquiry $(\mathrm{CoE})$ in order to take forward SoTL in higher education. We draw on Cassidy et al.'s (2008) and Christie et al.'s (2007) model of seven elements of a CoE to explore our own experience of forming a $\mathrm{CoE}$ emanating from an inter-institutional professional course on teaching and learning, which assisted us to collaboratively contribute to SoTL. The above model was found to be useful, but could be enhanced through an expanded perspective, incorporating the affective turn.
\end{abstract}

Keywords: academic development course, community of enquiry, collaborative writing, professional development, scholarship of teaching and learning

The Scholarship of Teaching and Learning (SoTL) in higher education, a concept originally coined by Boyer (1990), refers to one of a number of ways of being a scholar in academia. In order to transcend the binaries of 'the tired old teaching vs research debate' (Boyer, 1996: 131), four intertwined components of scholarship were proposed, in order to give scholarship a broader, more expansive meaning. The four functions of academic work according to Boyer (1990) include the scholarship of discovery, which is closest to the conventional concept of research and involves the discovery of new knowledge (investigation and enquiry); the scholarship of integration, where the meanings of knowledge are interpreted and integrated into disciplinary, inter-disciplinary and larger contexts; the scholarship of application - the application of knowledge to the social context and finally the scholarship of teaching, a communal act of sharing knowledge which is crucial to 'keeping the flame of scholarship alive' (Boyer, 1996: 132). 
More recent applications of SoTL conceptualise pedagogy as enquiry-focused and research-led (Roxå, Olsson, \& Mårtensson, 2008). SoTL is receiving increasing attention both locally and internationally, with academics in higher education institutions (HEIs) being encouraged to both reflect on and write about their own teaching and learning practices and experiences (Brew, 2007; Leibowitz \& Bozalek, 2016; Vithal, 2016). With regard to publishing in teaching and learning, sole-authored articles are the most highly prized by HEIs due to neoliberal imperatives such as funding formulae for research incentives and rewards. While encouragement for academics to publish on their own teaching may be wellintentioned, the expectations that academics will independently choose to research and write about their teaching rather than publishing in their own disciplinary field, often end in disappointing yields for SoTL and academic developers who see their role as promoting this within their institutions. One of the reasons for the lack of take-up of SoTL publishing is that academics who may be seasoned researchers in their own fields, often find themselves floundering when first engaging with research into their own teaching practices. This is especially true in STEM disciplines where academics have limited experience of educational research which is located in the social sciences or humanities, and may not see how aspects of their research expertise can contribute to educational research. Thus, although these educators could well be regarded and regard themselves as seasoned researchers in their own fields, in terms of SoTL they may still be novice and emerging researchers.

One way of addressing these issues which constrain the promotion of SoTL is to form communities of enquiry (CoEs) - which could be seen as communities of practice (CoPs) that focus specifically on enquiry. CoEs have the potential to provide a space for academics to come together to write about their teaching and learning experiences in a non-threatening, supportive and safe environment. These groups can comprise a mixture of those experienced in educational research and those who are novices, thus providing opportunities to gain confidence in SoTL through collaboration with others. This paper reports on the development of such a $\mathrm{CoE}$ that arose organically out of our involvement in a short inter-institutional course on Emerging Technologies (ET) to improve Teaching and Learning in Higher Education ${ }^{1}$.

While HEIs offer learning opportunities within and across faculties, inter-institutional learning and SoTL through collaborative subgroups is uncommon, particularly in South Africa. Even less commonly considered are the possibilities such professional development teaching and learning courses may provide for developing SoTL - which is the contribution that this paper is seeking to make. To this end, we share our journey of emergence into a $\mathrm{CoE}$ through a collaborative writing process from our involvement in the ET course. We make use of Cassidy et al.'s (2008) theoretical framework to elaborate on how this CoE came about through a reflexive account of our learning about collaboration. Cassidy et al. (2008) identified seven factors that need to be considered when building a $\mathrm{CoE}$ - namely opportunities for dialogue and participation, the quality of relationships, the perceptions and assumptions underlying the CoE, the structure and context, climate, purpose and control of

\footnotetext{
${ }^{1}$ The Emerging Technologies (ET) course is one of a number of inter-institutional short courses offered by the Cape Higher Education Consortium (CHEC) which are aimed at enhancing teaching and learning practices at higher education institutions (HEIs).
} 
the CoE. We use these factors to reflect on and collaboratively examine our own processes in becoming a $\mathrm{CoE}$, noting that this process is not the same for all groups. We also propose an additional category to consider as a factor contributing to establishing a $\mathrm{CoE}$ - that of affect.

The concept of communities of practice (CoP) was introduced by Lave and Wenger (1991). CoPs are not bounded, autonomous entities, but composed of individuals who are drawn together through dimensions of joint practice (Wenger, 1998). Christie et al. (2007: 266) extend this concept of CoP further with the notion of CoE defined as 'a special case of community of practice, where the practice in question is enquiry or research activity' frequently leading to knowledge generation. In this paper, we use the seven significant $\mathrm{CoE}$ factors mentioned above to review our own practice which flowed from our participation in the ET course. We explored the extent to which we developed a $\mathrm{CoE}$ in Cassidy et al.'s (2008) and Christie et al.'s (2007) terms. What follows is our exploration of the formation, journey and reflections by ourselves as a small group of educators in two different HEIs in Cape Town, South Africa, who moved from a closed, structured learning environment to an open self-generated research endeavour. We draw on our path of collaboration with mutual goals to reach a valued and enriching $\mathrm{CoE}$ which enabled our contributions to SoTL.

\section{Background}

A series of short courses were designed and developed under the auspices of the Cape Higher Education Consortium (CHEC), a body which coordinates various academic development courses across the local four higher education institutions in Cape Town, South Africa. The intention of these courses was to offer institutional collaboration across HEIs to amalgamate previously fragmented interventions in the field of teaching and learning. One such course was the ET course (see Bozalek, Ng'ambi \& Gachago, 2013 for more details of the course) designed to encourage educators to develop a deeper understanding for incorporating technology into their teaching rather than as an add-on to traditional approaches (Rowe, Bozalek \& Frantz, 2012). The course design used principles of dialogue and participation in face-to-face (f2f) and online environments. Participants each developed their own case studies on changing an aspect of their teaching and learning practice and received feedback from the facilitators and fellow participants on their weekly tasks towards the case study on an ongoing basis during the six week duration of the course. Our collective involvement in this course provided the catalyst for the formation of this CoE.

The authors and researchers of this paper are three participants ${ }^{2}$ who took part in the ET course in 2013 (Arona, Melanie and Veronica who work in Health Sciences Education in two HEIs and one facilitator (Vivienne, a Director of Teaching and Learning). The group members are all located in professional development, and engaged with facilitating teaching and learning. Among 23 others involved in the ET course, the three participants chose to work in a small group focused on the topic area of collaboration amongst other offerings such as digital stories, mobile technologies and social media. All course participants had to develop an authentic case study in their own contexts. In order to accomplish this task, the

\footnotetext{
${ }^{2}$ The participants taking part in these professional development short courses are academics and generally referred to as 'participants', not students.
} 
participants and facilitator met face-to-face and online, where dialogue took place through Adobe Connect and Google Drive in order to improve their case studies. Participants shared their weekly tasks online which cumulatively contributed to the development of their case studies. Group members and facilitators responded with formative feedback using the affordances (Bower, 2008) of Google Drive to make comments on each other's work.

While this project began as a learning opportunity for professional development using emerging technologies, it evolved into an informal, committed group connected in a virtual research environment (VRE) that acted as 'a platform for a diverse range of research activity' (Wilson et al., 2007: 290). At the end of the short course, we began a process of reflecting and writing together about our experience on the ET course and took up opportunities to present at local and international conferences on educational development. Subsequently we continued working together as a collaborative group (Bozalek, Mitchell, Dison \& Alperstein, 2016). Despite many challenges in writing collaboratively over an extended period of time, we persevered, sensing a shifting and enriching influence from working as a CoE. Thus a dialogic and participatory approach to our development as a collaborative research group continued in the co-construction of knowledge. In the next section we outline the process that we went through to reflect on our experience using Christie el.'s (2007) and Cassidy et al.'s (2008) framework for understanding a CoE.

\section{Methodology}

Our research is guided by a scholarly approach involving reflective practice conducted by researchers who are directly involved in the research setting, referred to as 'insider research' in higher education (Trowler, 2012; Robson, 2002). In a previous paper (Bozalek et al., 2016), we examined our experiences on the ET course through a political ethics of care framework (Tronto, 1993). In this paper we use a framework of factors considered significant when attempting to build a CoE (Christie et al., 2007; Cassidy et al., 2008). Drawing on this framework we reflect retrospectively on the unexpected formation of ourselves as a $\mathrm{CoE}$ which lends itself to a dialogical, collaborative and participatory approach for researching our teaching. We consider the extent to which our engagement could be regarded as a CoE, using data generated from our own reflections on working together as a group. To accomplish this, we each wrote up our own short text about how we as a group were functioning in relation to all seven factors significant for a $\mathrm{CoE}$ (Christie et al., 2007; Cassidy et al., 2008). We then individually took responsibility for going through the individual reflections of one or two of the seven factors, and for merging the different perspectives from our separate narratives. We then had further discussions on these categories reworking them and collaboratively making sense of each factor of the CoE framework in relation to our experience of our CoE.

\section{Seven factors of a community of enquiry}

In this section we examine our process of collaborative scholarship in relation to the seven factors of $\mathrm{CoE}$.

\section{Dialogue and participation}

Dialogue is central for the formation of a $\mathrm{CoE}$ and for facilitating a democratic, participatory approach to research and writing. Interaction in our group was characterised by dialogue both 
in our face-to-face engagements and in writing that was facilitated by the affordances of Google Drive over the three years of working collaboratively on this project. The free communication tools of Google Drive provided online dialogical spaces that enhanced the establishment and strength of our CoE enabling us to collaborate both synchronously and asynchronously. The side comment and chat options in Google Docs provided spaces for online dialogue and analysis at different times and intervals, and across our locations at different HEIs. Without these options, the dialogue would have been limited to $2 \mathrm{f}$ meetings or email communications. Furthermore $\mathrm{f} 2 \mathrm{f}$ meetings were not easy to organise with everyone's busy schedules. The opportunity for dialoguing online provided an important space for discussing differences and adding energy and impetus to multiple stages of editing that were necessary in working through the texts together. These online options for dialogue also enabled inclusive participation that was particularly valued by Veronica who has difficulty travelling to certain meeting locations due to her visual impairment and subsequent dependence on others for transport.

Christie et al. (2003) distinguish three levels of participation in a CoE - entry level, active membership, and close involvement. In our encounters with each other over time these levels varied in a dynamic way influenced by earlier relationships between group members and the characteristics associated with group phases (Northouse \& Northouse, 1999) that influenced our involvement with each other. In the beginning we were unsurprisingly tentative. The more we worked together getting to know each other through the co-authoring of papers and conference presentations, the more we developed increased and deeper dialogical communication. Presenting at conferences locally and abroad helped to forge lasting relationships that promoted our online dialogical communications. Although our connections with each other and the ongoing texts may have been uneven for group members, for instance those who did not attend conferences, our iterative working together and apart contributed to a strengthened collegial relationship.

Christie et al. (2007) emphasise the importance of the amount of time that a CoE has to establish relationships or build on existing relationships. Time to meet and time to work during the course on the shared project was problematic for this group for both the participants and the facilitator. The group members were extremely busy with academic, teaching and leadership commitments which conflicted with quick turnaround times between task posts and the due dates of the ET course. After the short course we recognised the potential for writing together over a longer time period in a more relaxed manner. More time for careful and deeper considerations in our writings could provide something new and productive.

\section{Relationships}

Relationships are central to a CoE. Cassidy et al. (2008: 224) argue that 'the quality of relationships within a community of practice or enquiry [are likely to] determine the degree to which it achieves its desired purpose'. Working relationships between academics are often characterised by inequality in relation to seniority, work experience and position. We recognised how the relationships in our group transitioned over time. Initially the feelings of anxiety and sometimes inadequacy in relation to other participants impacted on our engagement with each other on the course. Veronica was cautious about exposing her work to 
the group members. She said 'it took time to develop a trusting relationship' which was enabled by a non-judgemental approach and an interest in understanding the contexts of the different group members. By the time the group members began to work together after completion of the course, there was acknowledgement that a level of trust had been established.

Sharing work on Google Drive with each other could lead participants to feel vulnerable with increased anxiety about giving feedback online. Such tensions were ameliorated in the ET course by the supportive environment created by the facilitators and continued in our working together as a CoE. The quality of ideas were valued, 'rather than the status of the person expressing them' (Christie et al., 2007: 271). Openness, respect, fairness and listening were appreciated. These qualities according to Christie et al. (2007) make up the conditions which need to be in place for CoEs to flourish. Furthermore 'mutual trust, is a vital ingredient in enabling participants to have confidence to share their ideas' (Christie et al., 2007: 270-271). This was built up to a large extent between the three participants and facilitator within the duration of the short course.

The experience of collaborative interaction in the course laid the basis of relationshipbuilding when we as a group made the transition into reflection and writing beyond the course. At that point we had built up relationships of mutual trust, respect and confidence to express ourselves and know that we would be listened to. These conditions were further developed during our experiences of analysing the material in relation to different theoretical frameworks, preparing conference presentations and writing papers. Hierarchical relationships mitigate against working together in CoEs which foreground the need for participatory parity and social interaction on an equal footing (Fraser, 2013). The importance of trust is regarded as central for the sharing of ideas in dialogue and critical debate.

Vivienne (Viv) observed that the relationships between participants and facilitators in the ET course were less hierarchical than most learning situations and this contributed to an ease of communication among us. The fact that the participants were all working in health sciences education and shared an interest in the authentic tasks of the others facilitated our identification with each other and a common purpose. Course participants were able to and encouraged to share experiences regarding their practices and to find common threads of interest. Viv observed that 'as trust grew, participants were able to make themselves more vulnerable to each other and thus learn more from each other'. The development of trust and ease of communication was strengthened as the group shifted from the course context to that of an informal community of enquiry and gained more experience of working together.

Arona explored other overlapping relationships of the participants in particular work relationships, such as her relationship with Viv who holds a more senior position that she described as a 'sort-of reporting/guiding relationship'. She clarified that the relationship was not about the assertion of power. However she was still aware of this overlapping relationship in their work in the collaborative group. She said, 'Viv does not lead in a hierarchical way. However, I think I experience more of a desire to please or a fear of disappointing than I would have otherwise because of my work relationship with her'.

Technology was perceived as contributing to the building of relationships. Using Google Drive both in the course and in subsequent work facilitated writing together and dialogic interaction on our writing. There was a parallel process of participants becoming 
comfortable with giving and receiving feedback on Google Docs and developing relationships of trust as well as critical engagement as described in our paper (Bozalek et al., 2016).

\section{Perspectives and assumptions}

Christie et al. (2007) argue that an educational CoE is likely to benefit from incorporating a wide range of perspectives. We acknowledged the contributions of our different experiences and perspectives, as well as our commonalities through theory that contributed to the richness of the work produced.

All of us are convinced of the importance of relationships in higher education and in organisations and we are all interested in issues of social justice, participatory parity and student agency. Our shared academic development background provided access to a common language of enquiry. Our engagement with theory was extended through our collaborative writing process as we explored transdisciplinary philosophical approaches such as the political ethics of care (Tronto, 1993, 2013) and posthumanism (Barad, 2007). Viv identified an important part of the process in our $\mathrm{CoE}$ as 'sharing and familiarising ourselves with the underpinning knowledge and assumptions of these perspectives'. At the level of personal assumptions, Veronica compared her initial expectations with her experiences as the course unfolded and in the ensuing CoE. Initially she held the assumption that she would gain from the instruction of experts in the field within the set time period of the ET course and expected that subsequently 'it would all be up to me and my own agency'. Her expectations were exceeded when her learning was enhanced by the collaborative relationships and engagements that followed over an extended period of time expanded by the use of technology.

As Veronica noted, an 'inter-institutional learning space can be threatening as one moves out of the comfort of working with familiar colleagues and surroundings'. Through her experiences with and in hierarchical health sciences educational contexts she had become conditioned to the ruling order of line management and hegemonic views of those in more powerful positions. She appreciated the more equitable and dialogical approach to learning on the ET course and in the ongoing relationships with the group. She noted that 'as a parttime worker with less formal qualifications than others, I began to recognise that my contributions were valuable rather than viewed as irrelevant by those with more experience'.

\section{Structure and context}

Structure relates to the framework in which the group operates and the arrangements which make it possible to interact as a CoE. Structure could be influenced by physical and spatial enablements and constraints affecting group members, the group rules, as well as the positions that are ascribed to group members. Cassidy et al. (2008) note that structure can either be imposed from outside or within the group. In the ET course, structure was imposed by the curriculum design, consisting of weekly case study tasks and the requirement for group members to meet and give feedback to each other, both face-to-face and online.

When our CoE moved onto writing papers and presenting at conferences, the structure became negotiated amongst us. Viv observed that 'if we didn't have presentations to deliver, manuscripts to write, tasks to complete for the course, the communication wouldn't have 
been the same and the motivation to sustain the community of enquiry would not have been there'. The texts were given structure through the theoretical frameworks we used, and by the conference presentations and the journals we selected to write for. These forms of structure enabled the formation of a $\mathrm{CoE}$. Thus the formality of the professional development course dissolved into a more self-initiated process with more flexible arrangements designed to meet our needs. Viv, who was the facilitator on the course and took the lead in taking the group further, continued to provide leadership in an informal way.

\section{Climate}

Climate refers to the general mood, tone, control, interactive patterns and context in which the group interacts. Christie et al. (2007) note that while conflict is not necessarily a negative aspect of group interactions, there is the possibility that it could potentially have destructive consequences for relationships. In some communities, explicit rules are established early in the process to preempt possible negative consequences (Christie et al., 2007). At the start of this project we did not spend time expressing our assumptions and perceptions, despite its espoused usefulness for facilitating an accepting atmosphere for a $\mathrm{CoE}$ to develop. Rather, our group evolved organically through the conducive climate that emerged and the energy evoked through our keenness to continue our scholarship together.

The climate impacts on how confident and motivated people feel to make contributions to the CoE. It is important for a positive ethos to prevail for participants in the $\mathrm{CoE}$ to feel open to express their viewpoints and make contributions. Our group chose to rely on our trusting and respectful relationships rather than explicit rules. We tried to achieve a balance between critiquing and showing a mutual respectful attitude to each other's work and viewpoints.

The current higher education environment is fraught with imperatives to produce as many research outputs as possible (Connell, 2015; Jemielniak \& Greenwood, 2015) resulting in academics feeling anxious and pressurised rather than enthused about writing and researching. At an institutional level in higher education, the broad context for research tends to be characterised by such pressure and competitiveness. The consequences of not meeting institutional requirements for research are dire. Permanent posts and promotions depend on research productivity. Academics on contracts or on probation are vulnerable to not being reemployed if they do not meet research productivity requirements (Bozalek \& Carolissen, 2012). We deeply appreciated the microclimate generated in our CoE particularly within the broader context of competition and performativity in higher education which contrasted with individual experiences. For example Arona observed that the manner in which research productivity in universities was driven was 'punitive' rather than facilitative.

One consequence of the collaborative climate created in our CoE was increased confidence in the writing process. Melanie disclosed, 'I have a phobia about writing and this has given me...more confidence to write although I still have a long way to go'. Along the journey of writing together, there was very little conflict arising from our interactions as a group. Space was created for everyone's suggestions and points of view to be heard and acknowledged with encouragement and support which contributed towards the relaxed communications. Writing in the informal environment of a coffee shop enhanced the conducive climate. As Arona noted, 'our workplaces can feel quite stark and working 
together in a coffee-shop environment has added to the feeling that this is a fun and creative activity to be involved in and it is a break from an institutional environment'.

\section{Purpose}

In common with Lave and Wenger's CoP (1991), a CoE consists of members who have a common purpose and goal. This can be product-related, such as working towards publications or conference presentations, or working collaboratively with a group of co-enquirers from different professions to generate knowledge from different perspectives (Christie et al., 2007). We recognised that our CoE contributed to co-construction of knowledge across tertiary institutions with a common interest in sharing and learning more about dialogic feedback.

Purposes may be internally or externally generated - funded research projects, course participation, studying for further degrees may be some of the reasons for collaboration. Other purposes may be internally generated through working with colleagues across institutions who share similar interests in a research focus and wish to increase publication numbers. Whether externally or internally driven, a $\mathrm{CoE}$ is dependent upon a shared goal in a collaborative writing project.

Our group reflected on the purpose of participating in the ET course and the value of collaborative writing that emerged. Viv felt that the course was important for people to gain understanding of how emerging technologies could work in their own context which resonated with Arona and Melanie's reasons for choosing to be involved in the course and their participation in the collaborative group. Veronica was particularly keen to learn from others.

Beyond involvement in the course, new opportunities opened up to merge our thinking and practices into publications that matter and that carry weight in academia. Veronica reflected that although we were in the course for personal development, through the process we explored our 'narratable selves' (Taylor, 2014: 404) by sharing our stories of practice. Listening attentively to our colleagues' narratives enabled our development of deeper insights into our own practices and those of others. Through these exchanges Veronica recognised herself as an innovative teacher, willing to take risks in trying out new possibilities by immersing her teaching in technology.

Technology took on a vital and shifting role after our course as our focus shifted from learning to integrate technology to using technology in and through the collaborative writing project. Melanie observed that although we were 'at different stages with regard to publishing in our careers with different motivations for writing up our insights and experiences', we all gleaned unexpected benefit and fulfillment in the process and practice of writing together. Viv remarked that she found it an easy process, an egalitarian one, unlike some other collaborative writing projects in which she had been involved. Arona valued our common purpose in reflecting on our varied experiences, and then exploring them through multiple theoretical frameworks. We all had a desire to belong to a $\mathrm{CoE}$ through our involvement in the project, as expressed by Arona:

I was finding it difficult to write and publish on my own, and I had had some negative experiences of working with others on research projects. I was excited about the opportunity 
to work with Viv, Veronica and Melanie as I felt that there was a shared purpose and our interests and practices complemented each other... I thought that people's approaches to knowledge, research and philosophical approaches were compatible.

Improving our expertise in giving feedback was an additional purpose of the $\mathrm{CoE}$ and was invaluable for our practice as educators and facilitators. Our previous collaborative paper (Bozalek et al., 2016) explored how our writing together and apart produced new knowledge through dialogue and scholarship, provoking and generating new perspectives that questioned our underlying assumptions.

\section{Control}

Leadership was a more pertinent concept than 'control' in our CoE. Wenger, McDermott and Snyder (2002, cited in Christie et al., 2007) argue that all CoPs depend on leadership within the group and that healthy communities share that leadership across the group. According to Wenger et al. (2002) healthy communities rely on members taking on a number of roles. Individual roles and power relations are continually being negotiated and renegotiated (Christie et al., 2007). A group is more likely to move towards its desired goals when it relies on collaboration rather than individual competitiveness.

Viv, as facilitator on the ET course, initiated this project and continued to play a lowkey leadership role in the $\mathrm{CoE}$ for example, through identifying relevant readings and conferences for presentations. However the focus, choice of journals and timeline for writing have been negotiated by all of us with few tensions. Our writing process and the structure of presentations have been discussed with a sense of space and generosity for everyone to contribute, to be heard with a common plan mutually agreed on. For instance, both Arona and Melanie felt that Veronica had assumed more of a leadership role in the project by taking initiative and contributing extra work. Arona observed that 'through [Veronica's] engagement and insights her voice [was] strongly heard in the project'.

Veronica and Melanie reiterated that while leadership and initiation of the projects came from Viv, we all felt a sense of control. Ideas were responded to and options opened up. For instance, the initial sharing on Google Drive of relevant reading material by Viv demonstrated her generosity and willingness to let go of possession and control. We were offered these resources and the uptake was then an individual choice.

\section{Suggestions and challenges}

Through interrogating our collaborative writing experience, we recognise that affective intensities pervaded our practices. Affect was threaded through our intra-actions and our analysis, contributing a valuable component to the framework attributed to Christie et al. (2008) and Cassidy et al. (2007). Affect encompasses more than emotion as it draws on Spinoza's ideas of what a body can be and do in a relational context, described as 'a sense of vitality or vivacity, a sense of being more alive' (Massumi, in interview with Zournazi, 2015: 10). There is a growing awareness of affect as a significant concept in pedagogical inquiry. This turn to affect using Spinozist and Deleuzian affect theory enables new possibilities for SoTL (Gregg \& Seigworth, 2010; Massumi, 2015; Read, 2016). Affects are 'transindividual, passing in and through relations with others' (Read, 2016: 105). 
We recognise that the force and also the political intensity of affect has strongly influenced our CoE. Affect appears to have enabled our engaged interactions (Massumi, 2015). For example, we experienced the importance of generosity and openness towards each other that generated a sense of excitement and enthusiasm for motivating others. Generosity is not something which is mentioned either by Cassidy et al. (2008) or Christie et al. (2007), but Mary Zournazi (2002) foregrounds the importance of generosity and gift-giving for the development of hope and the recognition of the other's potential. We regard generosity to be an important affective quality for a $\mathrm{CoE}$ to flourish.

The generosity of group members in giving feedback and responding in sensitive ways elicited positive affective energy that contributed to our learning and continuing engagement. On the ET course, we chose to focus on the theme of collaboration. Veronica was attracted to the collaborative group because she felt the importance of working together rather than competitive individualistic achievement that is so entrenched in our educational system'. She related this specifically to medical education, arguing that 'many opportunities can open up if the context and culture of medical education can become more conducive to collaboration'. While we were drawn together by an interest in collaboration in education, this interest translated into our own active practice in collaborative writing and research, thus realising affirmative affective intensities that became transformative (Read, 2016). This was an unexpected and productive consequence of the affective forces generated in our continuing intra-actions, rather than an anticipated outcome of the ET course.

The model of CoE as outlined by Cassidy et al. (2008) and Christie et al. (2007) was found to be useful, but could be enhanced through an expanded perspective. Presently the $\mathrm{CoE}$ has a focus solely on a human-centred view where human interaction is foregrounded, leaving out considerations of non-human forces intra-acting ${ }^{3}$ with the human (Barad, 2007). We acknowledge that our relationships in the $\mathrm{CoE}$ were influenced by and enacted through entangled connections with each other as well as non-human actors such as Google Drive and the spaces and places where writing happened. Even our cups of cappuccino that displayed patterns created by the barista, contributed to the process of our coming together as a productive group.

Our emerging texts actively engaged with each other to produce something new. We understood this as a process of diffraction, as conceptualised by Karen Barad (2007) who puts forward the concept of diffraction in which differences come to matter through their interference with each other, like waves in the ocean. This has led to the development new layers of richness, in different and idiosyncratic ways, to the individual and collective projects. The texts themselves, transformed through Google Drive, were entangled in time, space and matter, influencing our interactions and intra-actions that 'signif[y] the mutual constitution of entangled agencies' (Barad, 2007: 33). In our collaborative writing efforts and numerous encounters, our intra-actions led to emerging insights that have informed this paper, and continue to dwell with us all.

\footnotetext{
${ }^{3}$ Karen Barad (2007) developed intra-action as a neologism where she distinguishes this from interaction. Interaction assumes separate entities which are relating to each other while intra-action is based on a relational ontology where relationships pre-exist entities and entities come into being through relationships.
} 


\section{Conclusion}

In this paper we examine how SoTL can be fostered through a professional development teaching and learning course which makes it possible for a $\mathrm{CoE}$ to emerge. We have described the development of our $\mathrm{CoE}$, and then worked through the seven factors put forward by Cassidy et al. (2008) and Christie et al. (2007) to discern what and how this framework has contributed to the generative impact of our mutual engagement. While our original incentive in working together was for professional development in the scholarship of teaching and learning, more was gained through our mutual enquiry as a CoE that provided opportunities for us to present and publish together and apart. The core elements of a $\mathrm{CoE}$ were described and identified in varying degrees in our collaboration, yet with and through the $\mathrm{CoE}$ we felt empowered to extend our work in a productive and generative manner with a sense of our becoming SoTL researchers.

The organised short ET course offered by CHEC across institutional boundaries provided the initial structure and impetus for the emergence of our CoE which then took on its own momentum with new purpose, renegotiated structure, deepened relationships and intensified dialogue and participation. Reflecting on our group involvement during and after the course in relation to Christie et al.'s (2007) and Cassidy et al.'s (2008) seven elements for a $\mathrm{CoE}$, we identified that the additional element of affect could be beneficial, making a rich contribution to developing and sustaining a CoE. Affective forces that emerge through our entangled relationships contribute a profound influence on our being and becoming with each other and our texts in the production of the CoE. A move beyond human-centred agency encourages us to recognise the vital role that matter such as texts can play in bringing together contributions and contributors towards a functioning and flourishing enquiring community that can generate new knowledge and insights.

The paper shows how inter-institutional short courses which provide spaces for CoPs to develop through close interactions between participants and facilitators can potentially move into CoEs which have the potential to be highly productive for the development of SoTL. The CoEs such as the one we were part of, can foster new possibilities for participants to become scholars of teaching and learning in supported environments, where both novice and experienced educational researchers have the opportunities to share their knowledge and experiences with each other. Such productive interactions can reap benefits for those involved and the broader educational SoTL community.

Vivienne Bozalek is a Professor of Social Work and the Director of Teaching and Learning at the University of the Western Cape, South Africa. Her research interests and publications include the political ethics of care and social justice, posthumanism and feminist new materialisms, innovative pedagogical practices in higher education, and post-qualitative and participatory methodologies.

Arona Dison is Co-ordinator of the Writing Centre and Teaching and Learning Specialist in the Directorate of Teaching and Learning at the University of the Western Cape. Her research interests include academic literacies, political ethics of care and research capacity development. 
Melanie Alperstein is a Senior Lecturer in the Department of Health Sciences Education in the Faculty of Health Sciences, University of Cape Town, South Africa. Her research interests are clinician education and student learning, engaged scholarship and indigenous health knowledge.

Veronica Mitchell is a $\mathrm{PhD}$ candidate at the University of the Western Cape and a facilitator in the Department of Obstetrics and Gynaecology at the University of Cape Town. Her physiotherapy background and her experiences in human rights education led to her interest in exploring the medical curriculum and students' becoming. Her publications include a research blog at http://phd4veronica.blogspot.co.za/, authored websites, and journal papers.

\section{References}

Barad, K. 2007. Meeting the universe halfway: Quantum physics and the entanglement of matter and meaning. Durham, NC: Duke University Press.

Boud, D. \& Molloy, E. 2013. Feedback in higher and professional education: Understanding it and doing it well. London: Routledge.

Bower, M. 2008. Affordance analysis - matching learning tasks with learning technologies. Educational Media International, 45(1): 3-15.

Bozalek, V., Mitchell, V., Dison, A. \& Alperstein, M. 2016. A diffractive reading of dialogical feedback through the political ethics of care. Teaching in Higher Education, 21(7): 825-838. DOI: 0.1080/13562517.2016.1183612.

Bozalek, V., Ng'ambi, D., \& Gachago, D. 2013. Transforming teaching with emerging technologies: Implications for higher education institutions. South African Journal of Higher Education, 27(2): 419-436.

Bozalek, V., McMillan, W., Marshall, D., November, M., Daniels, A. \& Sylvester, T. 2014. Analysing the professional development of teaching and learning at UWC from a political ethics of care perspective. Teaching in Higher Education, 19(5): 447-458.DOI: 10.1080/13562517.2014.880681.

Bozalek, V. \& Carolissen, R. 2012. The potential of critical feminist citizenship frameworks for citizenship and social justice in higher education. Perspectives in Education, 30(4): 9-18.

Boyer, E. 1990. Scholarship reconsidered: Priorities of the professoriate. Princeton, NJ: The Carnegie Foundation for the Advancement of Teaching.

Boyer, E. 1996. From Scholarship Reconsidered to Scholarship Assessed. Quest, 48:129-139.

Brew, A. 2007. Approaches to the scholarship of teaching and learning. In Brew, A. and Sachs, J. (eds.) Transforming a University: The Scholarship of Teaching and Learning in Practice. Sydney: Sydney University Press, 1-10.

Brown, J. S. \& Duguid, P. 1991. Organizational learning and communities of practice: towards a unified way of working, learning and innovating. Organizational Science, 2(1): 40-57.

Cassidy, C., Christie, D., Coutts, N., Dunn, J., Sinclair, C., Skinner, D., \& Wilson, A. 2008. Building communities of educational enquiry. Oxford Review of Education, 34(2): 217-235. 
Christie, D., Cassidy, C., Skinner, D., Coutts, N., Sinclair, C., Rimpilainen, S., \& Wilson, A. 2007. Building collaborative communities of enquiry in educational research. Educational Research and Evaluation: An International Journal on Theory and Practice, 13(3): 263-278.

Connell, R. 2015. Writing for Research. http://www.raewynconnell.net/ (Accessed 4 May 2016).

Fraser, N. 2013. Fortunes of feminism: From state-managed capitalism to neoliberal crisis. London: Verso.

Gregg, M. \& G. J. Seigworth (eds.). 2010. The affect theory reader. Durham and London: Duke University Press.

Herrington, J., Reeves, T. C. \& Oliver, R. 2010. A guide to authentic e-learning. New York \& London: Routledge.

Jemielniak, D. \& Greenwood, D. J. 2015. Wake Up or Perish: Neo-Liberalism, the Social Sciences, and Salvaging the Public University. Cultural Studies $\leftrightarrow$ Critical Methodologies, 15(1): 72-82.

Lave, J. \& Wenger, E. 1991. Situated learning: Legitimate peripheral participation. Cambridge: Cambridge University Press.

Leibowitz, B. \& Bozalek, V. 2016. The scholarship of teaching and learning from a social justice perspective. Teaching in Higher Education, 21(2): 109-122.

Massumi, B. 2015. Politics of affect. Cambridge: Polity.

Northouse, P.G. \& Northouse, L.J. 1999. Health communication strategies for professionals. Connecticut: Appleton and Lange.

Read, J. 2016. The Affective Economy: Producing and Consuming Affects in Deleuze and Guattari. In Meiborg, C. and Van Tuinen, S. (eds.) Deleuze and the Passions, New York: Punctum.

Robson, C. 2002. Real world research: A resource for social scientists and practitioner researchers. Massachussetts: Blackwell Publishers.

Rowe, M., Bozalek,V. \& Frantz, J. 2013. Using Google Drive to facilitate a blended approach to authentic learning. British Journal of Educational Technology, 44(4): 594-606.

Roxå, T., Ohlsson, T. \& Mårtensson, K. 2008. Appropriate use of theory in the scholarship of teaching and learning. Arts and Humanities in Higher Education, 7(3): 276-294.

Taylor, C. 2014. Telling transitions: space, materiality, and ethical practices in a collaborative writing workshop. Cultural Studies Critical. 14(4): 396-406.

Tronto, J. 1993. Moral boundaries: A political argument for an ethic of care. New York: Routledge.

Tronto, J. 2013. Caring democracy: Markets, equality and justice. New York: New York University Press.

Trowler, P. 2012. Doing insider research in universities. Kindle Book: Amazon Digital Services, Inc.

Vithal, R. 2016. Growing a scholarship of teaching and learning institutionally. Studies in Higher Education. DOI: 10.1080/03075079.2016.1180350

Wenger, E. 1998. Communities of practice: Learning, meaning and identity. Cambridge: Cambridge University Press. 
Wenger, E. 2000. Communities of practice and learning systems. Organization, 7(2): 225246.

Zournazi, M. 2002. Hope: New philosophies for change. New York: Routledge.

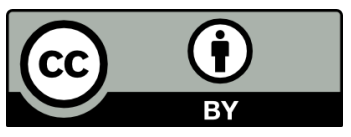

This publication is covered by a Creative Commons Attribution 4.0 International license. For further information please see: http://creativecommons.org/licenses/by/4.0/. 